\title{
Laboratory and Growth Chamber Evaluation of Fungicidal Seed Treatments for Maize Seedling Blight Caused by Fusarium Species
}

\author{
G. P. Munkvold and J. K. O’Mara, Department of Plant Pathology, Iowa State University, Ames 50011
}

\begin{abstract}
Munkvold, G. P., and O’Mara, J. K. 2002. Laboratory and growth chamber evaluation of fungicidal seed treatments for maize seedling blight caused by Fusarium species. Plant Dis. 86:143150 .

The performance of seed treatment products for maize usually is evaluated in field experiments, where it is difficult to assess their effects on specific important pathogens such as fungi in the genus Fusarium. To evaluate three fungicidal seed treatments (captan, difenoconazole, and fludioxonil) against six Fusarium species that infect maize seed or seedlings, we conducted experiments in the laboratory and in growth chambers. In the laboratory experiments, treated and nontreated seeds of two maize hybrids were incubated on the surface of an agar medium colonized by each of 12 Fusarium isolates. The fungi did not reduce seed germination, but most Fusarium isolates caused decay of the seed and radicle, and arrested the development of the radicle. All three fungicides significantly reduced the colonization and decay of the seeds and radicles by Fusarium isolates and resulted in greater radicle lengths, but there were significant interactions between the effects of fungicide treatments and Fusarium isolates. Overall, difenoconazole was the most effective fungicide for the prevention of seed colonization and decay. Fludioxonil was overall the most effective fungicide in terms of increased radicle length, particularly when seed was exposed to isolates of $F$. graminearum, which were among the most aggressive isolates in the experiments. In the growth chamber experiments, seeds were planted in a Fusarium-infested potting medium, which resulted in lower emergence, shoot length, root length, and dry weight of seedlings compared to the noninfested control. Some isolates also caused root rot symptoms. All three fungicides significantly improved shoot and root length and root health, difenoconazole and fludioxonil significantly improved emergence, and only difenoconazole significantly improved dry weight compared to the nontreated control. There were significant rank correlations between the results of the laboratory and growth chamber experiments in terms of relative aggressiveness of the isolates and relative efficacy of the fungicides. The laboratory experiments were more sensitive in terms of detecting differences in fungicide performance. These results indicate that all three fungicides were effective against Fusarium, but difenoconazole and fludioxonil generally were more effective than captan; the fungicides also differed in efficacy against different Fusarium species.
\end{abstract}

Additional keywords: Dividend, Fusarium moniliforme, F. oxysporum, F. proliferatum, F. solani, F. subglutinans, F. verticillioides, Maxim

Commercially produced seed of maize (Zea mays L.) is almost universally treated with a fungicide prior to sale to protect the seed from fungal infection after planting, or to deter the growth of seedborne fungal pathogens $(1,6)$. This practice has been recommended for maize in the United States since the 1930s $(15,33)$. In most cases, fungicide treatment of maize seed improves emergence and yield compared to nontreated seed $(23,25,27)$. The primary fungal genera targeted by maize seed treatments are Pythium Pringsh. and Fusarium Link (17). Currently, most maize seed planted in the United States is treated with a formulation of fludioxonil and me-

Corresponding author: G. P. Munkvold

E-mail: munkvold@iastate.edu

Accepted for publication 7 October 2001.

Publication no. D-2001-1203-01R

(C) 2002 The American Phytopathological Society fenoxam (Maxim XL, Syngenta Crop Protection, Greensboro, NC). The other major seed treatment fungicide used in the United States is captan (several formulations, Gustafson Inc., Plano, TX) in combination with metalaxyl (Allegiance, Gustafson Inc., Plano, TX). Captan and fludioxonil are broad-spectrum contact fungicides with activity against Fusarium species. Metalaxyl and mefenoxam are narrowspectrum systemic chemicals with activity limited to the Oomycetes (34). Although fludioxonil is not considered a systemic fungicide, a small percentage of seedapplied fludioxonil can be detected in internal seed tissues and the coleoptiles of germinating seeds (24). Difenoconazole (Dividend, Syngenta Crop Protection, Greensboro, NC) is a systemic fungicide that is not registered for use on maize in the United States, but is a widely used seed treatment for wheat and is reported to have excellent activity against Fusarium (17). Other fungicides are used on maize seed in different parts of the world for control of other diseases, but in the current study we were concerned only with fungicides that might play a role in control of seedling blights by Fusarium species.

Most published research on the efficacy of seed treatments for maize consists of reports of field tests performed under a variety of environmental conditions $(20,23,25,27)$. Field tests provide crucial information about the field performance of seed treated with these fungicides, but do not provide information about efficacy against specific fungi. In some of these studies, fungi were isolated from damaged seeds or seedlings $(3,5)$, but to elucidate the role of the isolated fungi in the etiology of seedling blight, further experimentation would have been necessary. Agricultural soils contain a mixture of potentially pathogenic fungi and other microorganisms that interact with the seeds and seedlings. The components of this mixture are different in every field test. Therefore, the results of a single field test or series of tests in a single location have limited predictive value for other soils. Only through a large number of field tests can the performance of a seed-treatment fungicide be evaluated with confidence. This approach can be unreliable in practice if insufficient field locations are employed or conditions are not sufficiently favorable for seedling disease (20).

Another approach to assessing the efficacy of seed-treatment fungicides is to evaluate their efficacy under controlled conditions against specific pathogenic fungi. Seed treatment manufacturers typically perform evaluations of this type during the product development process (22), but results are rarely published. Product labels generally indicate activity of products according to fungal genus; however, there is rarely information on efficacy at the species level for large and complex genera such as Pythium and Fusarium. Within these genera, distribution and pathogenicity of individual species varies significantly, therefore, it is important to evaluate efficacy of fungicides against individual species. Additionally, there is a need for information on the relative efficacy of the seed treatment products available or potentially available for use on maize.

Maize seeds and seedlings can be infected by several species in the genus Fusarium, particularly $F$. verticillioides (Sacc.) Nirenberg, (synonym F. moniliforme Sheldon), $F$. proliferatum (Matsushima) Nirenberg, F. subglutinans (Wol- 
lenweb. \& Rienking) Nelson, Toussoun, and Marasas, and $F$. graminearum Schwabe. These species can be seedborne $(9,13,21,28)$ or survive in the soil or crop residue $(7,31)$ and attack seeds and seedlings after planting $(9,17,32)$. Two other species, $F$. oxysporum Schlechtend.:Fr. and F. solani (Mart.) Sacc., are rarely seedborne but survive in the soil and frequently $(9,16,26,32)$.

The relative importance of seedborne vs. soilborne Fusarium in maize has been studied over many years by various researchers, but conflicting results have been obtained. Usually, $F$. verticillioides (reported as $F$. moniliforme) has been reported as the most common seedborne species $(15,16)$. In some cases, seedborne infection by this species appears to have little effect on seeds or seedlings $(9,20)$, whereas, in other cases it is associated with poor emergence and weak seedling growth $(4,10,14,15) . F$. graminearum can be seedtransmitted in maize (13) and can cause seedling blight in maize, barley, and wheat $(11,12,17)$. In general, however, seedborne infections by Fusarium spp. "rarely cause problems with seed germination of dent corn" (9), because modern seed conditioning processes remove severely infected seeds from hybrid seed lots.

The objectives of this study were to: (i) assess the efficacy of several fungicidal seed treatments against a group of Fusarium isolates representing the primary species that affect maize seedlings in North America, and (ii) evaluate a laboratory method for assessing efficacy of maize seed treatments against Fusarium spp. and aggressiveness of Fusarium isolates toward maize seeds.

Two types of experiments were conducted to evaluate seed treatments for protection from seedling blights caused by six infect the roots of maize seedlings

\section{MATERIALS AND METHODS}

species of Fusarium. In laboratory experiments, seedling blight symptoms were assessed in seedlings incubated on an agar medium colonized by isolates of Fusarium. The results of these experiments were compared to those of growth chamber experiments in which seedlings were grown in a Fusarium-infested potting medium.

Fusarium isolates. The following isolates were used in the experiments: $F$. graminearum ISUA66A and ISUA73B, isolated from kernels of maize grown in Iowa; F. oxysporum FRC O-1018 (Fusarium Research Center, Pennsylvania State University), isolated from roots of maize grown in Pennsylvania, and ISU94A1, isolated from roots of alfalfa grown in Iowa; F. proliferatum ISU93019 and ISU93310, isolated from kernels of maize grown in Iowa; F. solani FRC S-325 (Fusarium Research Center), isolated from roots of maize grown in Illinois, and ISU95C1, isolated from roots of maize grown in Iowa; F. subglutinans ISU93093 and ISU93177, isolated from kernels of maize grown in Iowa; and $F$. verticillioides ISU93009 and ISU93018, isolated from kernels of maize grown in Iowa. Identification of these isolates was by morphology, according to Nelson et al. (29) or, in the case of $F$. verticillioides, according to Nirenberg (30). Preliminary pathogenicity tests were performed only with isolates $F$. proliferatum, $F$. subglutinans, and $F$. verticillioides. In the preliminary tests, 20 isolates of each of these three species were tested for seedling pathogenicity. These isolates were originally obtained from infected kernels of maize grown in Iowa, and were single-spored prior to the experiments. The preliminary tests were conducted by planting seed into Fusariuminfested sand (8) and isolates were judged according to their ability to reduce plant height compared to noninoculated controls. The two isolates of each species that

Table 1. $F$ values for effects of Fusarium isolate and fungicidal seed treatment on fungal colonization, radicle length, germination, and seed/radicle decay of corn seed and seedlings at different temperatures $^{y}$

\begin{tabular}{|c|c|c|c|c|c|}
\hline \multirow[b]{2}{*}{ Dependent variable } & \multirow[b]{2}{*}{ Independent variable } & \multicolumn{4}{|c|}{ Temperature $\left({ }^{\circ} \mathbf{C}\right)$} \\
\hline & & 10 & 15 & 20 & 25 \\
\hline \multirow[t]{3}{*}{ Fungal colonization } & Isolate & $3.68 * z$ & $7.08 *$ & $2.86^{*}$ & $2.57 *$ \\
\hline & Fungicide & $48.90 *$ & $148.75^{*}$ & $209.94 *$ & $294.78 *$ \\
\hline & Isolate $\times$ fungicide & $2.44 *$ & $2.10^{*}$ & $2.99 *$ & $2.64 *$ \\
\hline \multirow{3}{*}{ Radicle length } & Isolate & $4.75^{*}$ & $11.65^{*}$ & $13.17 *$ & $8.64 *$ \\
\hline & Fungicide & $6.28^{*}$ & $24.27 *$ & $12.13^{*}$ & $8.58 *$ \\
\hline & Isolate $\times$ fungicide & 0.94 & $1.85^{*}$ & 0.88 & 0.64 \\
\hline \multirow[t]{3}{*}{ Germination } & Isolate & $9.22 *$ & $10.68^{*}$ & $4.79^{*}$ & $4.53 *$ \\
\hline & Fungicide & $23.92 *$ & $36.29 *$ & $10.03 *$ & $15.76^{*}$ \\
\hline & Isolate $\times$ fungicide & $2.37 *$ & $2.47 *$ & 0.95 & 1.51 \\
\hline \multirow[t]{3}{*}{ Seed/radicle decay } & Isolate & $7.84 *$ & $2.37 *$ & $26.44^{*}$ & $9.81 *$ \\
\hline & Fungicide & $4.12 *$ & $7.08 *$ & $11.37 *$ & $15.66^{*}$ \\
\hline & Isolate $\times$ fungicide & 0.96 & 0.93 & $2.24 *$ & 1.41 \\
\hline
\end{tabular}

y Values are based on two experiments with three replications of each treatment combination.

$\mathrm{z} *=P \leq 0.01 ;$ no asterisk $=P>0.05$. caused the greatest reductions in plant height were chosen for the laboratory and growth chamber studies.

Laboratory experiments. Five laboratory experiments were conducted using a method similar to that described by Altier and Thies for Pythium, (2). Each Fusarium isolate was cultured on carnation leaf agar (CLA) (29) and a spore suspension was prepared in sterile distilled water $\left(10^{6}\right.$ spores $/ \mathrm{ml})$. The suspension $(0.5 \mathrm{ml})$ was spread on the surface of a weak potato dextrose agar medium with antibiotics (3.9 $\mathrm{g}$ Difco potato dextrose agar (BectonDickinson), $10 \mathrm{~g}$ agar, $200 \mathrm{mg}$ streptomycin sulfate, $50 \mathrm{mg}$ chlorotetracycline $\mathrm{HCl}$, $120 \mathrm{mg}$ neomycin sulfate in 1.0 liter distilled water). Antibiotics were included to suppress the growth of seedborne bacteria. The cultures were incubated in the dark for 4 days, at which time the agar surface was completely colonized.

Seed of two maize hybrids (Pioneer Brand hybrid 3563 and Lynk's 13563) was treated with a single rate of one of the following fungicides: captan (Captan 400, $62.5 \mathrm{~g}$ a.i./100 $\mathrm{kg}$ seed), difenoconazole (Dividend 3FS, $24 \mathrm{~g}$ a.i./100 kg seed), or fludioxonil (Maxim 4FS, $2.5 \mathrm{~g}$ a.i./100 kg). Seeds were placed on the surface of the agar already colonized by Fusarium isolates and incubated in the dark for 2 weeks. Treatments were evaluated by assessing germination (seeds were considered germinated if the radicle was $>5 \mathrm{~mm}$ long), the percentage of seeds visibly colonized by the fungus, the percentage of seeds or radicles visibly decayed (seeds were considered decayed if either the seed or radicle was visibly rotted), and length of the radicle $(\mathrm{cm})$.

To identify the optimal temperature for incubation of seeds after placement on the colonized agar, an experiment was conducted twice with one hybrid (Pioneer Brand hybrid 3563) at four different temperatures. There were $10 \mathrm{Fusarium}$ isolates (ISU94A1 and ISU95C1 were not used) and a control consisting of the sterile agar medium. The experiment was a $4 \times 4 \times 11$ factorial, with four fungicide treatments (captan, difenoconazole, fludioxonil, and no fungicide) and four temperatures (10, 15,20 , and $25^{\circ} \mathrm{C}$ ). There were three replications of 10 seeds for each treatment combination. The three replications were arranged in a completely randomized design within each incubator. The experiments were continued until the radicle length in the noninoculated treatments reached approximately $2 \mathrm{~cm}$. This duration was 21 days for $10^{\circ} \mathrm{C}, 14$ days for $15^{\circ} \mathrm{C}$, and 9 days for 20 and $25^{\circ} \mathrm{C}$. Results for the two experiments were similar and were combined for analysis of variance. ANOVA was conducted separately for each temperature to assess the effects of fungicide treatment, fungal isolate, and their interaction on germination, colonization of seeds, radicle length, and seed/radicle decay. The 
results were evaluated by comparing $F$ values for the effects of fungal isolate, fungicide, and their interaction. The temperature at which the $F$ values were maximized for most of the dependent variables $\left(15^{\circ} \mathrm{C}\right)$ was judged to be the most effective temperature for distinguishing differences in fungal isolate or fungicide treatment. The other laboratory experiments were conducted with incubation at $15^{\circ} \mathrm{C}$.

Using the optimal temperature determined in the other two experiments $\left(15^{\circ} \mathrm{C}\right)$, an experiment was conducted three times with both hybrids and a 14-day duration, with 3 replications of 10 seeds each for each treatment combination. All 12 Fusarium isolates were included, along with a noninoculated control. ANOVA was conducted on the combined data from the three experiments with experiment as an independent variable and experimental observations consisting of the means for the 10 seeds in each petri dish. Mean separation of the treatments and Fusarium isolates was performed using the WallerDuncan $k$-ratio $(k=100)$ for main effects and the least-squares procedure (LSMEANS option in PROC GLM of SAS) for interacting effects. Spearman rank correlation analysis (SigmaStat, Jandel Scientific, San
Diego) was used to compare ranks for aggressiveness of Fusarium isolates and efficacy of fungicide treatments among the three experiments.

Growth chamber experiments. A growth chamber experiment was conducted three times with the same fungicide-treated seed used in the laboratory experiments. Inoculum of all 12 Fusarium isolates was prepared following a procedure modified from that of Desjardins et al. (8). A mixture of sand $(1,900 \mathrm{ml})$, corn meal $(380$ $\mathrm{ml})$, and water $(110 \mathrm{ml})$ was autoclaved in bags for $1 \mathrm{~h}$ at $121^{\circ} \mathrm{C}$ on two consecutive days. Each bag was then inoculated by

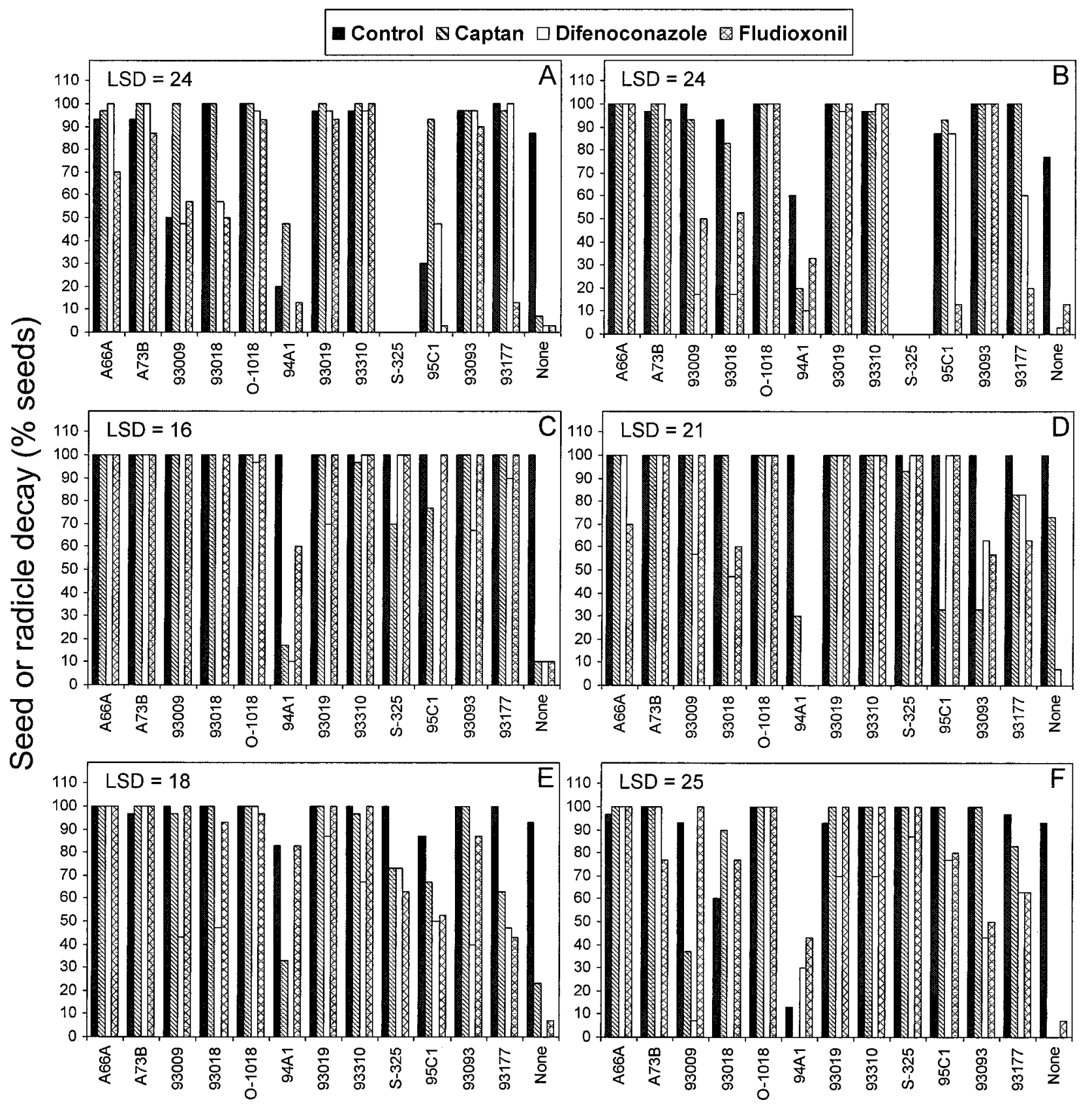

\section{Fusarium isolate}

Fig. 1. Decay of maize seed or radicles by Fusarium isolates in three laboratory experiments for evaluation of fungicidal seed treatment efficacy. A and B, Experiment 1; C and D, Experiment 2; and $\mathbf{E}$ and F, Experiment 3. A, C, and $\mathbf{E}$ are Pioneer brand hybrid 3563; B, D, and E are Lynk's Seeds hybrid 13563. LSD $=$ least significant difference according to least-squares means test, $\alpha=0.05$. Isolate $\mathrm{S}-325$ was not included in Experiment 1. 
injecting $2 \mathrm{ml}$ of a spore suspension $\left(10^{6}\right.$ spores $/ \mathrm{ml}$ ) of one of the Fusarium isolates, prepared from cultures on CLA. The bags were then incubated in the dark at ambient temperature $\left(20\right.$ to $\left.24^{\circ} \mathrm{C}\right)$ for 6 days, with mixing every day. Sterilized 21-cm-tall PVC cones were filled to $16 \mathrm{~cm}$ with sterilized sand. A small piece of paper towel was placed in the bottom of each cone to partially retard drainage. One seed per cone was placed on top of the sand and covered with $3 \mathrm{~cm}$ of the fungal inoculum (or sterile sand for the control). There were seven plants for each treatment combination. Treatments were randomized and placed in a growth chamber at $15^{\circ} \mathrm{C}, 50 \%$ relative humidity, and a $12-\mathrm{h}$ photoperiod. Emergence was assessed after 8, 13, and 20 days, and after 21 days, the plants were removed from the cones and washed. Root and shoot lengths were measured, and root health was assessed on a 1 to 5 scale: $1=$ lateral roots nearly absent and $>60 \%$ of root system with symptoms of decay, $2=$ lateral roots sparse and $>40$ to $60 \%$ root system with symptoms of decay, $3=$ lateral roots reduced and $>20$ to $40 \%$ root system with symptoms of decay, $4=$ well developed lateral roots and $\leq 20 \%$ root system with decay symptoms, and $5=$ well developed root system with negligible decay symptoms. Whole plants were oven-dried at $150^{\circ} \mathrm{C}$ for $24 \mathrm{~h}$ and weighed for comparison of plant dry weights among treatments.

ANOVA was conducted on data for emergence, shoot and root lengths, root health, and dry weight. Each experiment was considered as a replicate block for the analysis; individual observations were the means for the seven plants receiving a given treatment in each experiment. Mean separation was conducted using the WallerDuncan $k$-ratio $(k=100)$ to compare fungicide treatments and Fusarium isolates.

Spearman rank correlation analysis (SigmaStat) was used to compare results for the dependent variables from the laboratory experiments (germination, colonization, seed/radicle decay, and radicle length), and the dependent variables from the growth chamber experiments (emergence, shoot and root lengths, root health, and dry weight), with means for each fungicide treatment/Fusarium isolate combination serving as observations $(n=52)$.

\section{RESULTS}

Laboratory experiments. Fusarium isolates caused decay of the maize seeds and radicles and arrested radicle development in each experiment. In the experiments involving four temperatures, germination, fungal colonization, and radicle length were significantly $(P \leq 0.05)$ affected by Fusarium isolate, fungicide treatment, and their interaction (Table 1). Seed and radicle decay was significantly affected by isolate and fungicide treatment but not by the interaction. Main effects were significant for all four temperatures, but the interaction was significant only for some of the temperatures. $F$ values for these effects were typically highest at $15^{\circ} \mathrm{C}$; therefore, the other experiments were conducted at this temperature. The aggressiveness rankings of the Fusarium isolates (as determined by their effects on germination and radicle length) were similar among temperatures from 15 to $25^{\circ} \mathrm{C}$ (data not shown).

In experiments conducted at $15^{\circ} \mathrm{C}$ with two hybrids, there were significant interactions between the effects of experiment and hybrid and the effects of other independent variables. Therefore, experiments and hybrids were analyzed separately.

Germination ranged from 96.7 to $100 \%$ among the treatment combinations and experiments. There were no significant effects of fungal isolate or fungicide treatment on germination of seed in any of the three experiments (data not shown). For both hybrids in each experiment, the main effects of Fusarium isolate, fungicide treatment, and their interaction were significant $(P<0.0001)$ in terms of seed colonization, radicle length, and incidence of decay symptoms. Incidence of seed colonization by the Fusarium isolates differed among treatments, but generally was high (70 to $100 \%$ of seeds or seedlings) (data not shown). Incidence of seed and radicle decay also was generally high, but differed more among treatments (Fig. 1) than did colonization. Some fungicide treatments reduced incidence of seed colonization or seed/radicle decay to less than $10 \%$ for some Fusarium isolates. Difenoconazole was overall the most effective treatment for reducing seed colonization and decay. It significantly reduced seed colonization and decay in each of the six experiment/hybrid comparisons, and had the lowest mean incidence of seed colonization and decay in most of the comparisons (Table 2). In least-square means comparisons against the nontreated control for specific Fusarium isolates, captan significantly reduced seed colonization in 15 comparisons, difenoconazole significantly reduced seed colonization in 34 comparisons, and fludioxonil, in 22 comparisons. For seed/radicle decay, the captan treatment was significantly different from the nontreated control in 18 comparisons, whereas difenoconazole and fludioxonil differed from the nontreated control in 34 and 28 comparisons, respectively (Fig. 1). The noninoculated controls demonstrated signs of fungal colonization and symptoms of seed and radicle decay apparently due to seedborne fungi. All three fungicides significantly reduced seed and radicle decay in the noninoculated control. Radicle length was more variable among treatments than seed colonization or decay (Fig. 2). Fludioxonil was the most effective treatment for increasing radicle length. This fungicide significantly increased radicle length in each of the six experi-

Table 2. Effects of fungicidal seed treatments on fungal colonization of seed, seed/radicle decay, and radicle length in seedlings incubated on an artificial culture medium with isolates of six Fusarium species ${ }^{y}$

\begin{tabular}{|c|c|c|c|c|c|c|c|}
\hline \multirow[b]{2}{*}{ Variable } & \multirow[b]{2}{*}{ Fungicide $^{\mathrm{z}}$} & \multicolumn{3}{|c|}{ Pioneer hybrid 3563} & \multicolumn{3}{|c|}{ Lynk's hybrid 13563} \\
\hline & & Exp. 1 & Exp. 2 & Exp. 3 & Exp. 1 & Exp. 2 & Exp. 3 \\
\hline Colonization (\%) & $\begin{array}{l}\text { Captan } \\
\text { Difenoconazole } \\
\text { Fludioxonil } \\
\text { None }\end{array}$ & $\begin{array}{l}87.8 \mathrm{a} \\
61.9 \mathrm{c} \\
32.8 \mathrm{~d} \\
74.4 \mathrm{~b}\end{array}$ & $\begin{array}{r}94.6 \mathrm{~b} \\
52.9 \mathrm{c} \\
100.0 \mathrm{a} \\
100.0 \mathrm{a}\end{array}$ & $\begin{array}{r}96.9 \mathrm{~b} \\
96.9 \mathrm{~b} \\
100.0 \mathrm{a} \\
99.5 \mathrm{ab}\end{array}$ & $\begin{array}{l}36.4 \mathrm{~b} \\
30.6 \mathrm{~b} \\
39.5 \mathrm{~b} \\
83.1 \mathrm{a}\end{array}$ & $\begin{array}{r}73.1 \mathrm{c} \\
64.1 \mathrm{~d} \\
77.9 \mathrm{~b} \\
100.0 \mathrm{a}\end{array}$ & $\begin{array}{l}81.0 \mathrm{~b} \\
69.7 \mathrm{c} \\
93.3 \mathrm{a} \\
99.0 \mathrm{a}\end{array}$ \\
\hline Seed/radicle decay (\%) & $\begin{array}{l}\text { Captan } \\
\text { Difenoconazole } \\
\text { Fludioxonil } \\
\text { None }\end{array}$ & $\begin{array}{l}86.4 \mathrm{a} \\
70.0 \mathrm{~b} \\
56.1 \mathrm{c} \\
80.3 \mathrm{a}\end{array}$ & $\begin{array}{r}82.3 \mathrm{c} \\
57.2 \mathrm{~d} \\
95.4 \mathrm{~b} \\
100.0 \mathrm{a}\end{array}$ & $\begin{array}{l}81.0 \mathrm{~b} \\
57.9 \mathrm{c} \\
83.1 \mathrm{~b} \\
96.9 \mathrm{a}\end{array}$ & $\begin{array}{l}82.2 \mathrm{~b} \\
65.8 \mathrm{c} \\
67.4 \mathrm{c} \\
92.5 \mathrm{a}\end{array}$ & $\begin{array}{r}80.5 \mathrm{~b} \\
73.6 \mathrm{c} \\
73.1 \mathrm{c} \\
100.0 \mathrm{a}\end{array}$ & $\begin{array}{l}77.7 \mathrm{~b} \\
57.4 \mathrm{c} \\
79.0 \mathrm{~b} \\
88.2 \mathrm{a}\end{array}$ \\
\hline Radicle length (cm) & $\begin{array}{l}\text { Captan } \\
\text { Difenoconazole } \\
\text { Fludioxonil } \\
\text { None } \\
\end{array}$ & $\begin{array}{l}2.3 \mathrm{~b} \\
2.4 \mathrm{ab} \\
2.6 \mathrm{a} \\
1.7 \mathrm{c} \\
\end{array}$ & $\begin{array}{l}2.4 \mathrm{c} \\
3.0 \mathrm{~b} \\
3.2 \mathrm{a} \\
2.1 \mathrm{~d} \\
\end{array}$ & $\begin{array}{l}2.8 \mathrm{c} \\
3.1 \mathrm{~b} \\
3.3 \mathrm{a} \\
2.6 \mathrm{~d} \\
\end{array}$ & $\begin{array}{l}2.7 \mathrm{~b} \\
2.5 \mathrm{c} \\
3.0 \mathrm{a} \\
1.8 \mathrm{~d} \\
\end{array}$ & $\begin{array}{l}2.7 \mathrm{c} \\
3.1 \mathrm{a} \\
2.9 \mathrm{~b} \\
2.1 \mathrm{~d} \\
\end{array}$ & $\begin{array}{l}3.4 \mathrm{c} \\
3.6 \mathrm{~b} \\
3.8 \mathrm{a} \\
2.7 \mathrm{~d} \\
\end{array}$ \\
\hline
\end{tabular}

${ }^{y}$ Values are means for three replications of 10 seeds each for 12 Fusarium isolates (two isolates each of $F$. graminearum, F. oxysporum, F. proliferatum, F. solani, F. subglutinans, and F. verticillioides) and a noninoculated control. The three experiments were analyzed separately. Within each dependent variable, values in a column followed by the same letter are not significantly different, according to the Waller-Duncan $k$-ratio test, $k=100$.

${ }^{\mathrm{z}}$ Fungicides were applied to seed at recommended rates (captan, $62.5 \mathrm{~g}$ a.i.; difenoconazole, $24 \mathrm{~g}$ a.i.; fludioxonil, $2.5 \mathrm{~g}$ a.i./100 kg seed) using a small batch seed treater. 
ment/hybrid comparisons, and had the highest mean length in five of the six comparisons (Table 2). Radicle lengths for the captan treatment were significantly different from the nontreated control in 24 comparisons, whereas difenoconazole and fludioxonil differed from the nontreated control in 35 and 46 comparisons, respectively (Fig. 2). Radicle lengths for $F$. graminearum-inoculated treatments were significantly increased by fludioxonil in each experiment.

Among the three experiments, Spearman rank correlations were all highly signifi- cant $(P \leq 0.001)$ for seed colonization, seed/radicle decay, and radicle length. Rank correlations among experiments were $R=0.74$ to 0.89 for the fungicide treatments and $R=0.47$ to 0.77 for Fusarium isolates.

Growth chamber experiments. There were no significant $(P \leq 0.05)$ differences between the two hybrids in terms of emergence, shoot length, root length, or root health; however, there were differences in dry weight $(P \leq 0.0001)$. There were no significant interactions among the effects of hybrid, fungicide treatment, and Fusa- rium isolate for any of the variables measured. Emergence after 8 and 13 days was affected by Fusarium isolate $(P \leq 0.0001)$ but not by fungicide treatment $(P=0.18$ and 0.29) (data not shown). Emergence after 20 days was affected by fungicide treatment $(P=0.0092)$ and Fusarium isolate $(P \leq 0.0001)$. Between days 13 and 20, additional seedlings emerged and some previously emerged seedlings died. The fludioxonil and difenoconazole treatments had significantly higher emergence than the nontreated control. There were no significant differences among the three fungi-
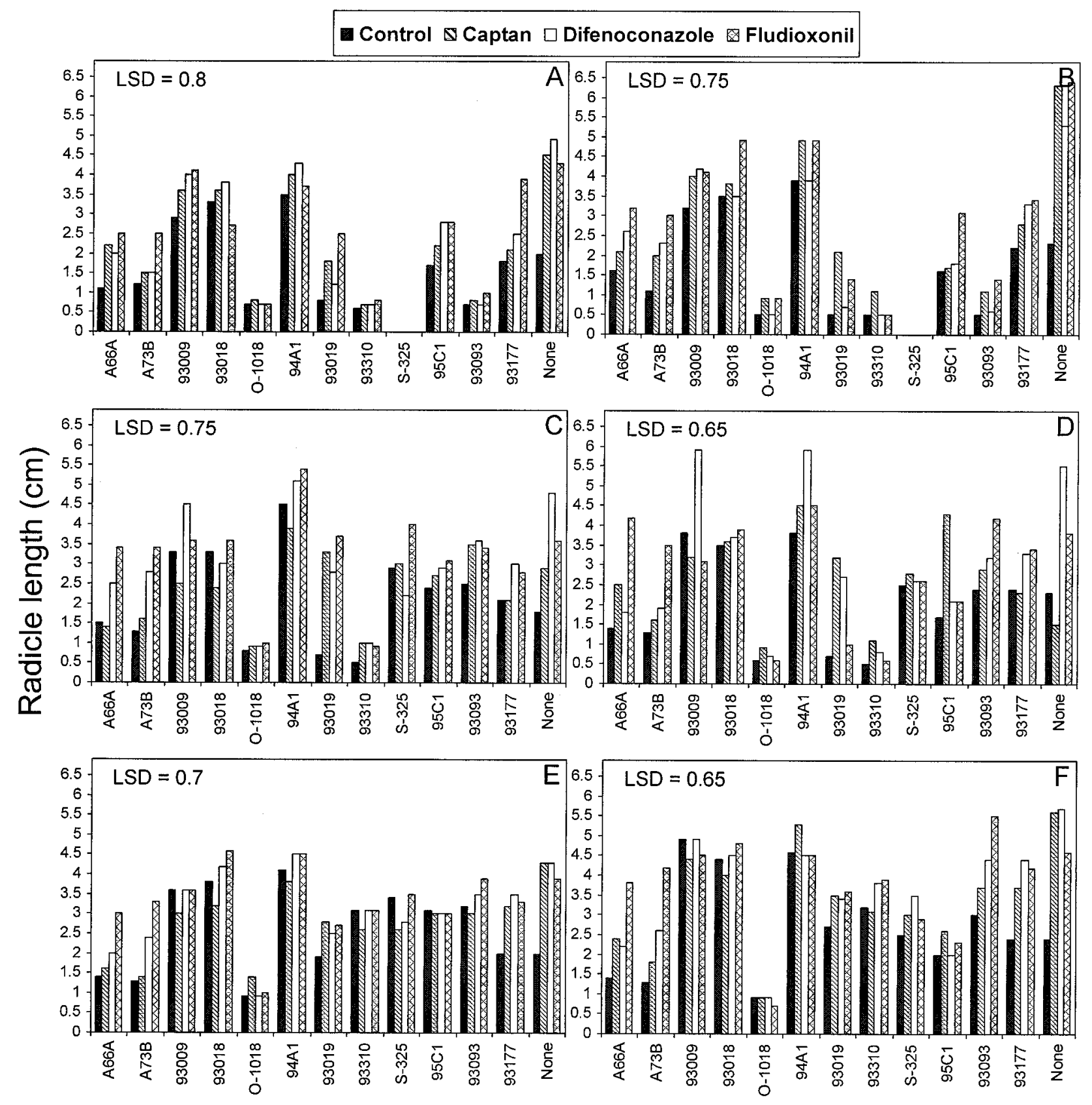

\section{Fusarium isolate}

Fig. 2. Lengths of radicles of maize seedlings grown in the presence of Fusarium isolates in three laboratory experiments for evaluation of fungicidal seed treatment efficacy. A and B, Experiment 1; C and D, Experiment 2; and $\mathbf{E}$ and F, Experiment 3. A, C, and E are Pioneer brand hybrid 3563; B, D, and E are Lynk's Seeds hybrid 13563. LSD = least significant difference according to least-squares means test, $\alpha=0.05$. Isolate S-325 was not included in Experiment 1. 
Table 3. Emergence, mean shoot and root lengths $(\mathrm{cm})$, root health ratings, and dry weights of corn seedlings grown from fungicide-treated or nontreated seed after 20 days (emergence) or 21 days (other variables) incubation in a growth chamber in a Fusarium-infested potting medium ${ }^{\mathrm{y}}$

\begin{tabular}{|c|c|c|c|c|c|c|}
\hline \multirow[b]{2}{*}{ Isolate } & \multirow[b]{2}{*}{ Fusarium species } & \multicolumn{4}{|c|}{ Seed Treatment } & \multirow[b]{2}{*}{ Mean } \\
\hline & & Captan & Difenoconazole & Fludioxonil & None & \\
\hline \multicolumn{7}{|c|}{ Emergence (\% of planted seeds) } \\
\hline $\mathrm{A} 66 \mathrm{~A}$ & F. graminearum & 61.9 & 81.0 & 81.0 & 47.6 & $67.9 \mathrm{e}$ \\
\hline A73B & F. graminearum & 42.9 & 50.0 & 78.6 & 31.0 & $50.6 \mathrm{f}$ \\
\hline 93009 & F. verticillioides & 83.3 & 88.1 & 83.3 & 95.2 & $87.5 \mathrm{a}-\mathrm{c}$ \\
\hline 93018 & F. verticillioides & 88.1 & 81.0 & 90.5 & 88.1 & $86.9 \mathrm{bc}$ \\
\hline O-1018 & F. oxysporum & 81.0 & 83.3 & 78.6 & 71.4 & $78.6 \mathrm{c}-\mathrm{e}$ \\
\hline $94 \mathrm{~A} 1$ & F. oxysporum & 97.6 & 100.0 & 100.0 & 95.2 & $98.2 \mathrm{a}$ \\
\hline 93019 & $F$. proliferatum & 83.3 & 71.4 & 81.0 & 66.7 & $75.6 \mathrm{de}$ \\
\hline 93310 & F. proliferatum & 85.7 & 76.2 & 78.6 & 71.4 & $78.0 \mathrm{c}-\mathrm{e}$ \\
\hline S325 & F. solani & 100.0 & 100.0 & 95.2 & 73.8 & $92.3 \mathrm{ab}$ \\
\hline $95 \mathrm{C} 1$ & F. solani & 78.6 & 83.3 & 92.9 & 95.2 & $87.5 \mathrm{a}-\mathrm{c}$ \\
\hline 93093 & F. subglutinans & 88.1 & 90.5 & 92.9 & 88.1 & $89.9 \mathrm{ab}$ \\
\hline 93177 & F. subglutinans & 95.2 & 88.6 & 85.7 & 73.8 & $85.7 \mathrm{~b}-\mathrm{d}$ \\
\hline \multirow[t]{2}{*}{ None } & None & 78.6 & 95.2 & 92.9 & 88.1 & $88.7 \mathrm{a}-\mathrm{c}$ \\
\hline & Mean & $81.9 \mathrm{AB}$ & $83.7 \mathrm{~A}$ & $87.0 \mathrm{~A}$ & $75.8 \mathrm{~B}$ & 82.1 \\
\hline \multicolumn{7}{|c|}{ Mean shoot lengths $(\mathrm{cm})$} \\
\hline A66A & F. graminearum & 9.2 & 10.8 & 12.0 & 6.7 & $9.7 \mathrm{de}$ \\
\hline A73B & $F$. graminearum & 5.3 & 5.3 & 11.0 & 2.4 & $6.1 \mathrm{f}$ \\
\hline 93009 & F. verticillioides & 11.0 & 10.2 & 11.1 & 10.6 & $10.7 \mathrm{~cd}$ \\
\hline 93018 & F. verticillioides & 9.5 & 9.8 & 8.5 & 7.8 & $8.9 \mathrm{e}$ \\
\hline O-1018 & F. oxysporum & 10.2 & 10.6 & 9.9 & 8.2 & $9.7 \mathrm{de}$ \\
\hline 94A1 & F. oxysporum & 15.3 & 16.1 & 15.5 & 14.5 & $15.4 \mathrm{a}$ \\
\hline 93019 & $F$. proliferatum & 8.3 & 10.0 & 8.9 & 8.3 & $8.9 \mathrm{e}$ \\
\hline 93310 & $F$. proliferatum & 15.9 & 11.2 & 12.1 & 9.2 & $12.1 \mathrm{c}$ \\
\hline S 325 & F. solani & 15.3 & 15.3 & 15.7 & 12.1 & $14.6 \mathrm{ab}$ \\
\hline $95 \mathrm{C} 1$ & F. solani & 15.2 & 15.8 & 15.3 & 14.3 & $15.1 \mathrm{a}$ \\
\hline 93093 & F. subglutinans & 14.0 & 14.9 & 14.0 & 14.1 & $14.2 \mathrm{ab}$ \\
\hline 93177 & F. subglutinans & 11.0 & 11.4 & 12.6 & 9.0 & $11.0 \mathrm{~cd}$ \\
\hline None & None & 14.0 & 14.0 & 13.3 & 12.9 & $13.6 \mathrm{~b}$ \\
\hline & Mean & $11.9 \mathrm{~A}$ & $11.9 \mathrm{~A}$ & $12.3 \mathrm{~A}$ & $10.0 \mathrm{~B}$ & 11.5 \\
\hline Mean root & & & & & & \\
\hline A66A & F. graminearum & 9.5 & 10.3 & 14.5 & 7.9 & 10.5 ef \\
\hline A73B & $F$. graminearum & 5.7 & 4.5 & 11.1 & 2.4 & $5.9 \mathrm{ij}$ \\
\hline 93009 & F. verticillioides & 8.3 & 6.3 & 6.6 & 6.8 & $7.0 \mathrm{hi}$ \\
\hline 93018 & F. verticillioides & 4.8 & 5.7 & 4.0 & 3.8 & $4.6 \mathrm{j}$ \\
\hline O-1018 & F. oxysporum & 7.9 & 10.3 & 8.0 & 7.9 & $8.5 \mathrm{f}-\mathrm{h}$ \\
\hline $94 \mathrm{~A} 1$ & F. oxysporum & 17.6 & 21.1 & 17.1 & 15.1 & $17.7 \mathrm{a}$ \\
\hline 93019 & $F$. proliferatum & 6.2 & 9.1 & 7.9 & 6.6 & $7.5 \mathrm{hi}$ \\
\hline 93310 & $F$. proliferatum & 15.4 & 9.9 & 9.2 & 6.3 & $10.2 \mathrm{fg}$ \\
\hline S 325 & F. solani & 15.6 & 13.6 & 13.6 & 10.3 & $13.3 \mathrm{~cd}$ \\
\hline $95 \mathrm{C} 1$ & F. solani & 20.2 & 14.1 & 14.6 & 14.4 & $15.7 \mathrm{ab}$ \\
\hline 93093 & F. subglutinans & 11.2 & 14.6 & 11.9 & 12.7 & $12.6 \mathrm{de}$ \\
\hline 93177 & F. subglutinans & 8.9 & 7.8 & 10.0 & 5.6 & $8.1 \mathrm{i}-\mathrm{h}$ \\
\hline None & None & 15.9 & 14.5 & 16.4 & 14.0 & $15.2 \mathrm{bc}$ \\
\hline & Mean & $11.2 \mathrm{~A}$ & $10.9 \mathrm{~A}$ & $11.2 \mathrm{~A}$ & $8.8 \mathrm{~B}$ & 10.5 \\
\hline Root health & $e)^{\mathbf{z}}$ & & & & & \\
\hline A66A & F. graminearum & 2.8 & 2.8 & 4.0 & 2.2 & $2.9 \mathrm{de}$ \\
\hline A73B & F. graminearum & 1.8 & 1.6 & 3.1 & 1.5 & $2.0 \mathrm{gh}$ \\
\hline 93009 & F. verticillioides & 2.8 & 2.3 & 2.3 & 2.4 & $2.4 \mathrm{fg}$ \\
\hline 93018 & F. verticillioides & 1.9 & 2.3 & 2.0 & 1.7 & $2.0 \mathrm{~h}$ \\
\hline O-1018 & F. oxysporum & 2.5 & 2.8 & 2.6 & 2.4 & $2.6 \mathrm{ef}$ \\
\hline 94A1 & F. oxysporum & 4.5 & 4.8 & 4.8 & 4.3 & $4.6 \mathrm{a}$ \\
\hline 93019 & F. proliferatum & 2.0 & 2.8 & 2.4 & 2.2 & $2.4 \mathrm{f}-\mathrm{h}$ \\
\hline 93310 & $F$. proliferatum & 3.7 & 2.7 & 2.8 & 1.9 & $2.8 \mathrm{ef}$ \\
\hline S 325 & F. solani & 4.1 & 3.9 & 3.9 & 3.0 & $3.7 \mathrm{bc}$ \\
\hline $95 \mathrm{C} 1$ & F. solani & 4.4 & 4.2 & 4.3 & 3.8 & $4.2 \mathrm{ab}$ \\
\hline 93093 & F. subglutinans & 3.1 & 3.5 & 3.4 & 3.4 & $3.4 \mathrm{~cd}$ \\
\hline 93177 & F. subglutinans & 2.8 & 2.8 & 3.2 & 2.2 & $2.7 \mathrm{ef}$ \\
\hline None & None & 3.8 & 3.7 & 4.1 & 3.5 & $3.8 \mathrm{bc}$ \\
\hline & Mean & $3.1 \mathrm{~A}$ & $3.1 \mathrm{~A}$ & $3.3 \mathrm{~A}$ & $2.7 \mathrm{~B}$ & 3.0 \\
\hline Dry weight & & & & & & \\
\hline A66A & F. graminearum & 1.54 & 1.68 & 1.58 & 1.31 & $1.53 \mathrm{bc}$ \\
\hline A73B & $F$. graminearum & 1.34 & 1.30 & 1.40 & 1.06 & $1.27 \mathrm{e}$ \\
\hline 93009 & F. verticillioides & 1.45 & 1.41 & 1.46 & 1.50 & $1.45 \mathrm{~cd}$ \\
\hline 93018 & F. verticillioides & 1.44 & 1.46 & 1.32 & 1.31 & $1.38 \mathrm{de}$ \\
\hline O-1018 & F. oxysporum & 1.36 & 1.56 & 1.39 & 1.48 & $1.45 \mathrm{~cd}$ \\
\hline $94 \mathrm{~A} 1$ & F. oxysporum & 1.78 & 2.00 & 1.90 & 1.76 & $1.86 \mathrm{a}$ \\
\hline 93019 & $F$. proliferatum & 1.38 & 1.52 & 1.44 & 1.42 & $1.44 \mathrm{~cd}$ \\
\hline 93310 & $F$. proliferatum & 1.69 & 1.43 & 1.50 & 1.50 & $1.53 \mathrm{bc}$ \\
\hline S 325 & F. solani & 1.61 & 1.59 & 1.76 & 1.66 & $1.65 \mathrm{~b}$ \\
\hline $95 \mathrm{C} 1$ & F. solani & 1.81 & 1.94 & 1.96 & 1.68 & $1.84 \mathrm{a}$ \\
\hline 93093 & F. subglutinans & 1.46 & 1.68 & 1.45 & 1.52 & $1.53 \mathrm{bc}$ \\
\hline 93177 & F. subglutinans & 1.41 & 1.43 & 1.39 & 1.39 & $1.40 \mathrm{de}$ \\
\hline None & None & 1.60 & 1.66 & 1.70 & 1.65 & $1.65 \mathrm{~b}$ \\
\hline & Mean & $1.52 \mathrm{AB}$ & $1.59 \mathrm{~A}$ & $1.56 \mathrm{AB}$ & $1.48 \mathrm{~B}$ & 1.54 \\
\hline
\end{tabular}

$\mathrm{y}$ Values are means of three replications of 14 plants per treatment (seven plants each of two hybrids). Values in a row followed by the same upper-case letter or in a column followed by the same lower-case letter are not significantly different according to the Waller-Duncan $k$-ratio test, $k=100$.

${ }^{\mathrm{z}}$ Root health was evaluated visually on a scale of 1 to 5 in which $1=$ lateral roots nearly absent and $>60 \%$ of root system with symptoms of decay, $2=$ lateral roots sparse and $>40$ to $60 \%$ root system with symptoms of decay, $3=$ lateral roots reduced and $>20$ to $40 \%$ root system with symptoms of decay, $4=$ well developed lateral roots and $\leq 20 \%$ root system with decay symptoms, and $5=$ well developed root system with negligible decay symptoms. 
cide treatments. Emergence differed significantly among plants inoculated with different Fusarium isolates. Isolate ISUA73B ( $F$. graminearum) consistently caused the lowest emergence, whereas isolate ISU94A1 ( $F$. oxysporum) consistently had among the highest levels of emergence (Table 3).

There were significant effects of fungicide treatment $(P \leq 0.0011)$ and Fusarium isolate $(P \leq 0.0001)$ on shoot length, root length, and root health (Table 3). All three fungicide treatments resulted in significantly greater shoot and root lengths compared to the nontreated control, and significantly less severe root decay (higher root health ratings) than the nontreated control. The fungicide treatments were not significantly different from each other in terms of shoot length, root length, or root health. Isolate ISUA73B ( $F$. graminearum) and ISU93019 $(F$. proliferatum) consistently caused the most inhibition of shoot growth, and isolates ISU94A1, both isolates of $F$. solani, and ISU93093 (F. subglutinans) consistently had no effect on shoot length (Table 3). Isolates ISUA73B and ISU93018 ( $F$. verticillioides) consistently caused the greatest reductions in root length and root health, whereas isolates ISU94A1, both isolates of $F$. solani, and ISU93093 consistently had no effect on root length or root health (Table 3). Fungicide treatment $(P=0.0489)$ and Fusarium isolate $(P \leq 0.0001)$ significantly affected plant dry weight. Only difenoconazole had dry weight significantly higher than the nontreated control, but dry weights were not significantly different among the three fungicide treatments. Results for dry weight were consistent with the other results in terms of the most and least aggressive Fusarium isolates (Table 3 ).

There were significant $(P<0.001)$ rank correlations among the dependent variables for the laboratory and growth chamber experiments (Table 4). In the laboratory experiments, radicle length was positively correlated with germination and negatively correlated with fungal colonization and seed/radicle decay. Fungal colonization and seed/radicle decay were positively correlated. In the growth chamber experiments, all the dependent variables were positively correlated. There also were significant correlations between dependent variables from the laboratory experiments and the growth chamber experiments (Table 4).

\section{DISCUSSION}

This study demonstrated that all three fungicidal seed treatments are effective against several Fusarium species that are pathogenic to maize seedlings. In general, difenoconazole and fludioxonil were more effective than captan, although captan was significantly better than the other fungicides for specific symptoms caused by some of the Fusarium isolates. The variable most commonly used to evaluate seed treatment performance is emergence. Only difenoconazole and fludioxonil significantly increased emergence compared to the nontreated control, although there were no significant differences among the three fungicide treatments. We did not observe effects on seed germination in our experiments, except for the initial laboratory experiments (Table 1). Those experiments were conducted with only one of the two maize hybrids used in the other experiments, and the seeds were from a different seed lot than those used in the remainder of the experiments.

In this study, we used only one rate of each fungicide. The captan rate was within the range specified on the product label (although our rate was approximately 14\% higher than the most commonly used commercial rate), the fludioxonil rate was the standard rate for maize seed, and the rate of difenoconazole was the lowest rate specified for this product for use on wheat. There is no registration for difenoconazole on maize in the United States. These rates represent a realistic comparison of commercial use of these seed treatments, but our conclusions are limited to the rates that we evaluated.

Most of the Fusarium isolates used in the study were pathogenic to maize seed- lings, but a few were not. Aggressiveness of the isolates varied as much within a species as among species. The high Spearman rank correlations (Table 4) among experiments demonstrated that the aggressiveness rankings of Fusarium isolates were similar among all the experiments, although there were some differences. Both the growth chamber and laboratory experiments identified some isolates (A73B, O-1018, and 93019) that were consistently aggressive pathogens (Figs. 1 and 2, Table 3). Other isolates appeared to be more aggressive either in the laboratory (93310) or growth chamber (93018) experiments. Both methods also identified isolates (94A1 and 95C1) that consistently failed to demonstrate pathogenicity to maize seedlings. In some cases, these nonpathogenic isolates significantly enhanced emergence and seedling growth compared to the noninoculated control (Fig. 2, Table 3), suggesting that they may have suppressed naturally occurring seedborne fungi.

Both evaluation methods were informative in terms of assessing the performance of the fungicides against Fusarium species. The growth chamber results were less variable, but the laboratory experiments were less time-consuming and more sensitive than the growth chamber experiments in detecting differential effects of the fungicide treatments. In the growth chamber experiments, there were no significant differences among the three fungicides, although difenoconazole was the only treatment that was always significantly different from the nontreated control. In the laboratory experiments, we detected some significant differences among the fungicide treatments (Table 2, Figs. 1 and 2). Although there were some different results among the three repetitions of the laboratory experiment, they were consistent in terms of treatment trends. Difenoconazole was generally more effective than captan and fludioxonil in terms of preventing fungal colonization and decay of the seeds and radicles. Fludioxonil was generally more effective than the other two fun-

Table 4. Spearman rank correlations for dependent variables measured in laboratory and growth chamber experiments for assessing the interactions between fungicidal seed treatments and Fusarium isolates on maize seedlings $(n=52)^{\mathrm{y}}$

\begin{tabular}{|c|c|c|c|c|c|c|c|c|c|}
\hline \multirow[b]{2}{*}{ Experiments } & \multirow[b]{2}{*}{ Variables } & \multicolumn{3}{|c|}{ Laboratory experiments } & \multicolumn{5}{|c|}{ Growth chamber experiment } \\
\hline & & Colonization & Decay & Radicle length & Emergence & Shoot length & Root length & Root health & Dry weight \\
\hline Laboratory & $\begin{array}{l}\text { Germination } \\
\text { Colonization } \\
\text { Decay } \\
\text { Radicle length }\end{array}$ & -0.15 & $\begin{array}{l}-0.08 \\
0.87 * * \mathrm{z}\end{array}$ & $\begin{array}{c}0.38 * \mathrm{z} \\
-0.64 * * \\
-0.72 * *\end{array}$ & $\begin{array}{c}0.10 \\
-0.60 * * \\
-0.60 * * \\
0.60 * *\end{array}$ & $\begin{array}{c}0.05 \\
-0.55^{* *} \\
-0.55^{* *} \\
0.35^{*}\end{array}$ & $\begin{array}{c}0.04 \\
-0.43^{* *} \\
-0.48^{* *} \\
0.26\end{array}$ & $\begin{array}{c}0.03 \\
-0.52^{* *} \\
-0.56^{* *} \\
0.34^{*}\end{array}$ & $\begin{array}{c}0.01 \\
-0.38^{*} \\
-0.42^{* *} \\
0.26\end{array}$ \\
\hline Growth chamber & $\begin{array}{l}\text { Emergence } \\
\text { Shoot length } \\
\text { Root length } \\
\text { Root health }\end{array}$ & & & & & $0.68 * *$ & $\begin{array}{l}0.50 * * \\
0.89 * *\end{array}$ & $\begin{array}{l}0.59 * * \\
0.92^{* *} \\
0.96^{* *}\end{array}$ & $\begin{array}{l}0.48^{* *} \\
0.82^{* *} \\
0.85^{* *} \\
0.84^{* *}\end{array}$ \\
\hline
\end{tabular}

${ }^{\mathrm{y}}$ Germination $=\%$ seed that produced a radicle at least as long as the seed after 2 weeks; colonization $=\%$ seeds with visible fungal mycelium after 2 weeks; decay $=\%$ seeds with visible decay of the seed or radicle after 2 weeks; radicle length $=$ length of radicle in $\mathrm{cm}$ after 2 weeks; emergence $=\%$ of seed that emerged from the potting medium after 20 days; shoot length $=$ length of shoots in $\mathrm{cm}$ after 21 days; root length $=$ length of primary root in $\mathrm{cm}$ after 21 days; root health $=$ assessment of root rot symptoms with $1=$ severely decayed roots and $5=$ healthy roots

$\mathrm{z} * P \leq 0.05 ; * * P \leq 0.01$. 
gicides in terms of promoting more rapid radicle growth (Table 2). In the laboratory experiments, there also were differential effects of the fungicides against individual Fusarium isolates. Fludioxonil and difenoconazole were more effective against isolates A66A, A73B, (F. graminearum) and 93177 ( $F$. subglutinans) than they were against isolate O-1018 ( $F$. oxysporum). Difenoconazole and fludioxonil were significantly better than captan in many of the single-isolate comparisons (Figs. 1 and 2), whereas captan was significantly better in relatively fewer comparisons. Fludioxonil was more effective than the other two fungicides against $F$. graminearum.

The laboratory method differed from that of Altier and Thies (2) because we measured specific seed and seedling symptoms instead of using a numerical scale to encompass several different symptoms. The 1 to 5 scale used in that study (2) included consideration of seed and radicle decay and whether the seed had germinated. The illustration of that scale (Fig. 1 of reference 2) also indicates that radicle length was consistently correlated with disease rating. In our study, radicle length was the characteristic that differed the most among treatments, and there were correlations among the symptom measurements and radicle length. It would be feasible to combine the symptom measurements we made into a numerical scale that would be more convenient to use.

In the growth chamber experiments, we chose to use a sterilized sand medium in order to avoid contamination with other fungi. A more poorly drained potting medium may have enhanced seedling disease and more closely mimicked field conditions. Although planting treated seeds into a fungus-infested potting medium is a straightforward method for evaluating the efficacy of maize seed treatments, there are few published examples. Mao et al. $(18,19)$ successfully used such a method to evaluate biological control agents as seed treatments, using a potting medium infested with a combination of Pythium spp. and $F$. graminearum. A captan treatment was included for comparison. In cotton, seed treatment with carboxin-PCNB was evaluated by planting into a potting medium infested with Pythium ultimum or Rhizoctonia solani (35). Neither of these examples involved comparisons among chemical seed treatments. More frequent use of such methods for seed treatment comparisons would provide more information on efficacious seed treatments for specific pathogens, increasing the precision of seedling disease management.

\section{ACKNOWLEDGMENTS}

We are grateful to Denis McGee, Iowa State University, and Laura Sweets, University of Missouri, for reviewing the manuscript. Journal paper J-19380 of the Iowa Agriculture and Home Economics Experiment Station, Project 3549, supported by Hatch Act and state of Iowa funds.

\section{LITERATURE CITED}

1. Agarwal, V. K., and Sinclair, J. B. 1997. Principles of Seed Pathology, 2nd ed. CRC Press, Inc., Lewis Publishers, Boca Raton, FL.

2. Altier, N. A., and Thies, J. A. 1995. Identification of resistance to Pythium seedling diseases in alfalfa using a culture plate method. Plant Dis. 79:341-346

3. Arias-Rivas, B., Mcgee, D. C., and Burris, J. S. 1998. Tratamiento de semillas de maiz con polimeros para el control de Pythium spp. Fitopatol. Venez. 11:10-15.

4. Bacon, C. W., Hinton, D. M., and Richardson, M.D. 1994. A corn seedling assay for resistance to Fusarium moniliforme. Plant Dis. 78:302-305.

5. Baird, R. E., Nankam, C., Moghaddam, P. F., and Pataky, J.K. 1994. Evaluation of seed treatments on shrunken-2 sweet corn. Plant Dis. 78:817-821.

6. Bergstrom, G. C. 1991. Fungicide benefits assessment - field crops north. Natl. Agric. Pesticide Impact Assessment Program.

7. Cotten, T. K., and Munkvold, G. P. 1998. Survival of Fusarium moniliforme, F. proliferatum, and $F$. subglutinans in maize stalk residue. Phytopathology 88:550-555.

8. Desjardins, A. E., Plattner, R. D., Nelsen, T. C., and Leslie, J. F. 1995. Genetic analysis of fumonisin production and virulence of Gibberella fujikuroi mating populaiton A (Fusarium moniliforme) on maize (Zea mays) seedlings. Applied Environ. Microbiol. 61:79-86.

9. Dodd, J. L., and White, D. G. 1999. Seed rot, seedling blight, and damping-off. Pages 10-11 in: Compendium of Corn Diseases, 3rd ed. D. G. White, ed. The American Phytopathological Society, St. Paul, MN

10. Futrell, M. C., and Kilgore, M. 1969. Poor stands of corn and reduction of root growth caused by Fusarium moniliforme. Plant Dis. Rep. 53:213-215.

11. Gilbert, J., Tekauz, A., and Woods, S. M. 1997. Effect of storage on viability of Fusarium head blight-affected spring wheat seed. Plant Dis. 81:159-162.

12. Jones, R. K. 1999. Seedling blight development and control in spring wheat damaged by Fusarium graminearum Group 2. Plant Dis. 83:1013-1018.

13. Kabeere, F., Hampton, J. G., and Hill, M. J. 1997. Transmission of Fusarium graminearum (Schwabe) from maize seeds to seedlings. Seed Sci. Technol. 25:245-252.

14. Kim, W. G., Oh, I. S., Yu, S. H., and Park, J. S. 1984. Fusarium moniliforme detected in seeds and its pathological significance. Korean J. Mycol. 12:105-110.

15. Koehler, B., and Holbert, J. R. 1930. Corn diseases in Illinois: their extent, nature, and control. Univ. Ill Agric. Exp. Stn. Bull. 354.

16. Kommedahl, T., and Windels, C. E. 1981. Root-, stalk-, and ear-infecting Fusarium species on corn in the USA. Pages 94-103 in Fusarium: Diseases, Biology, and Taxonomy. P. E. Nelson, T. A. Toussoun, and R. J. Cook, eds. Pennsylvania State University Press, University Park.
17. Lipps, P. E., and Deep, I. W. 1994. Seed treatment for agronomic crops. Bull. 639, Ohio State University Extension.

18. Mao, W., Lewis, J. A., Hebbar, P. K., and Lumsden, R.D. 1997. Seed treatment with a fungal or a bacterial antagonist for reducing corn damping-off caused by species of $P y$ thium and Fusarium Plant Dis. 81:450-454.

19. Mao, W., Lumsden, R. D., Lewis, J. A., Hebbar, P. K. 1998. Seed treatment using preinfiltration and biocontrol agents to reduce damping-off of corn caused by species of $P y$ thium and Fusarium. Plant Dis. 82:294-299.

20. McGee, D. C. 1981. Seed pathology: its place in modern seed production. Plant Dis. 65:638642 .

21. McGee, D. C. 1988. Maize Diseases: a Reference Source for Seed Technologists. The American Phytopathological Society, St. Paul, $\mathrm{MN}$.

22. McGee, D. C. 1995. Epidemiological approach to disease management through seed technology. Annu. Rev. Phytopathol. 33: 445-466.

23. Mohan, S. K., Knott, E. A., and Wilson, D. O., Jr. 1994. Effect of seed treatments on stand establishment in supersweet sweet corn, 1993. Fungicide and Nematicide Tests 50:295.

24. Mueller, K., Fischer, W., Steinemann, A., and Leadbitter, N. 1998. Control of Fusarium spp. on wheat: movement and efficacy of fludioxonil applied as a seed treatment. Cereal Res. Commun. 25:787-788.

25. Munkvold, G. P., and Carlton, W. M. 1996 Evaluation of seed treatment fungicides for corn, 1995. Fungicide and Nematicide Tests $51: 286$.

26. Munkvold, G. P., and Leslie, J. F. 1999. Fusarium root rot diseases. Page 13 in: Compendium of Corn Diseases, 3rd ed. D. G. White, ed. The American Phytopathological Society, St. Paul, MN

27. Munkvold, G. P., and Shriver, J. M. 2000 Evaluation of seed treatment fungicides for corn, 1999. Fungicide and Nematicide Tests 55:432.

28. Nelson, P. E. 1992. Taxonomy and biology of Fusarium moniliforme. Mycopathologia 117:2936.

29. Nelson, P. E., Toussoun, T. A., and Marasas, W. F. O. 1983. Fusarium Species: an Illustrated Manual for Identification. Pennsylvania State University Press, University Park.

30. Nirenberg, H. 1976. Untersuchungen ber die morphologische und biologische differenzierung in der Fusarium - Sektion Liseola. Mitt. Biol. Bundesant. Land-Fortwirtsch. Berlin-Dahlem 169:1-117.

31. Nyvall, R. F., and Kommedahl, T. 1970. Saprophytism and survival of Fusarium moniliforme in corn stalks. Phytopathology 60: 1233-1235.

32. Ocamb, C. M., and Kommedahl, T. 1994. Rhizosphere competence of Fusarium species colonizing corn roots. Phytopathology 84:166-172.

33. Porter, R. H., and Layton, D. V. 1936. Dust treatments for seed corn diseases. Iowa State Coll. Ext. Cir. 221.

34. Thomson, W. T. 1997. Agricultural Chemicals, Book IV - Fungicides, 12th ed. Thomson Publications, Fresno, CA

35. Wang, H., and Davis, R. M. 1997. Susceptibility of selected cotton cultivars to seedling disease pathogens and benefits of chemical seed treatments. Plant Dis. 81:10851088 . 